\title{
Article \\ Blood Count Recovery Following Induction Therapy for Acute Myeloid Leukemia in Children Does Not Predict Survival
}

\author{
Lauren Pommert ${ }^{1,2,+}{ }^{D}$, Todd M. Cooper ${ }^{3, *,+}$, Robert B. Gerbing ${ }^{4}$, Lisa Brodersen ${ }^{5}$, Michael Loken ${ }^{5}$, \\ Alan Gamis ${ }^{6}$, Richard Aplenc ${ }^{7}$, Todd A. Alonzo ${ }^{8}$ and Edward Anders Kolb ${ }^{9}$
}

1 Division of Oncology, Cancer and Blood Diseases Institute, Cincinnati Children's Hospital Medical Center, Cincinnati, OH 45229, USA; lauren.pommert@cchmc.org

2 Department of Pediatrics, University of Cincinnati College of Medicine, Cincinnati, OH 45229, USA

3 Division of Hematology/Oncology, Cancer and Blood Disorders Center, Seattle Children's Hospital, Seattle, WA 98105, USA

4 Children's Oncology Group, Monrovia, CA 91016, USA; rgerbing@childrensoncologygroup.org

5 Hematologics Inc., Seattle, WA 98121, USA; Lisa@hematologics.com (L.B.); mrloken@hematologics.com (M.L.)

6 Children's Mercy Hospital and Clinics, Kansas City, MO 64108, USA; agamis@cmh.edu

7 Division of Oncology, The Children's Hospital of Philadelphia, Philadelphia, PA 19104, USA; aplenc@chop.edu

8 Department of Population and Public Health Sciences, University of Southern California, Los Angeles, CA 90032, USA; talonzo@childrensoncologygroup.org

9 Nemours Center for Cancer and Blood Disorders/Nemours Children's Health, Wilmington, DE 19803, USA; Edward.Kolb@nemours.org

* Correspondence: Todd.cooper@seattlechildrens.org; Tel.: +1-206-987-2106

+ These authors contributed equally to this work.

\section{check for}

updates

Citation: Pommert, L.; Cooper, T.M.; Gerbing, R.B.; Brodersen, L.;

Loken, M.; Gamis, A.; Aplenc, R.; Alonzo, T.A.; Kolb, E.A. Blood Count Recovery Following Induction Therapy for Acute Myeloid Leukemia in Children Does Not Predict Survival. Cancers 2022, 14, 616. https://doi.org/10.3390/ cancers14030616

Academic Editor: David Wong

Received: 22 November 2021

Accepted: 21 January 2022

Published: 26 January 2022

Publisher's Note: MDPI stays neutral with regard to jurisdictional claims in published maps and institutional affiliations.

Copyright: (C) 2022 by the authors. Licensee MDPI, Basel, Switzerland. This article is an open access article distributed under the terms and conditions of the Creative Commons Attribution (CC BY) license (https:// creativecommons.org/licenses/by/ $4.0 /)$.
Simple Summary: International Working Group (IWG) and European LeukemiaNet (ELN) adult response definitions are currently used to evaluate the efficacy of new agents for childhood acute myeloid leukemia (AML); however, the criteria are not consistent with consensus definitions used in pediatric trials or the common practice of intensifying treatment prior to full hematopoietic recovery of ANC $\geq 1000$ cells $/ \mu \mathrm{L}$ and platelets $\geq 100$ cells $/ \mu \mathrm{L}$. This retrospective analysis of the two most recent Phase 3 AML trials in the Children's Oncology Group assesses the incidence, timing, and prognostic significance of count recovery following induction chemotherapy in children with AML. These data confirm that awaiting count recovery to meet adult criteria does not reflect standard practice in pediatric AML and IWG/ELN-defined CR does not have a significant impact on survival in children. Continuing to use adult IWG/ELN count recovery definitions limits childhood AML drug development by underestimating response, and therefore, updated response criteria are needed for pediatric AML patients.
Abstract: International Working Group (IWG) and European LeukemiaNet (ELN) response defi- nitions are utilized to evaluate the efficacy of new agents for childhood acute myeloid leukemia (AML) for regulatory purposes. However, these criteria are not consistent with definitions used in pediatric AML trials or with standard pediatric practice to proceed with subsequent therapy cycles prior to IWG/ELN-defined count recovery. We retrospectively analyzed data from the two most recent Phase 3 pediatric AML clinical trials conducted by the Children's Oncology Group (COG) to assess the incidence, timing, and prognostic significance of count recovery following induction chemotherapy. Of the patients with fewer than $5 \%$ bone marrow blasts at the end of first induction, $21.5 \%$ of patients proceeded to a second induction cycle prior to achieving ANC $\geq 500$ cells $/ \mu \mathrm{L}$ and platelets $\geq 50,000$ cells $/ \mu \mathrm{L}$, both well below the IWG/ELN thresholds of ANC $>1000$ cells $/ \mu \mathrm{L}$ and platelets $>100,000$ cells $/ \mu \mathrm{L}$. In these two sequential childhood AML Phase 3 trials, neither ANC nor platelet recovery predicted survival. Intensification of treatment through the initiation of subsequent therapy cycles prior to attainment of IWG/ELN-defined CR is common practice in clinical trials for children with AML, suggesting that updated response definitions are needed for pediatric AML. 
Keywords: pediatric acute myeloid leukemia; childhood acute myeloid leukemia; clinical trial response assessment; IWG criteria

\section{Introduction}

Acute myeloid leukemia (AML) in children and adults represent a phenotypically heterogeneous and genetically complex subtype of hematopoietic malignancies. There are approximately 20,000 newly diagnosed cases of AML in the United States each year with an average age at diagnosis of 68 years; however, fewer than 500 of these cases occur in children under the age of 15 . Given this differential age distribution [1], clinicians have long assumed that AML observed in older adults is distinct from that seen in children. Age is not a defining characteristic of AML according to the World Health Organization (WHO); rather, the category of AML with recurrent genetic abnormalities captures many of the structural variants seen in more than $50 \%$ of children with AML and fewer than $15 \%$ of older adults [2-4]. Assessment of treatment response for children and adults with AML in the United States is currently based on the International Working Group (IWG) criteria, first published in 1990 [5] and updated in 2003 [6]. The IWG criteria require a peripheral complete blood count $(\mathrm{CBC})$ and histologic quantification of bone marrow blasts by microscopy, and define complete response (CR) as fewer than $5 \%$ bone marrow blasts with an absolute neutrophil count (ANC) $>1000$ cells $/ \mu \mathrm{L}$ and platelets (plt) $>100,000$ cells $/ \mu \mathrm{L}$. Similar criteria are followed by the European LeukemiaNet (ELN) in adults with AML [7]. These response criteria have remained the standard by which the efficacy of new drugs is measured in clinical trials in both adults and children.

In 2010, Walter et al. demonstrated clearly that in adult AML patients treated 15 to 35 years ago, it was routine to await count recovery at the end of induction to evaluate for residual dysplasia [8]. During this 19-year study period, $97 \%$ of adult patients with less than $5 \%$ blasts had platelet count recovery to greater than 100,000 cells $/ \mu \mathrm{L}$ after initial induction therapy, and count recovery was associated with improved survival. These data support the IWG and ELN response criteria for AML in adults. Recognizing that these criteria have never been validated in children, herein we assess the incidence of count recovery and its prognostic impact on survival in children with AML treated in the most recent AML trials from the Children's Oncology Group (COG). We hypothesized that the adult IWG/ELN criteria do not predict survival in pediatric patients.

\section{Materials and Methods}

\subsection{Patients}

We retrospectively analyzed data from the two most recent Phase 3 pediatric clinical trials for de novo AML conducted by the COG in the United States. The eligibility, therapy, and results for these trials have been previously reported $[9,10]$. The CONSORT diagrams describing patients analyzed in this dataset are included in Figure 1. Data from the COG cohort include more than 2700 patients 1-29 years of age with AML diagnosed between 2006 and 2018 and enrolled in AAML0531 (NCT00372593) [9] and AAML1031 (NCT01371981) [10]. Patients with Down syndrome AML (DS-AML) in AAML0531 $(n=6)$ were excluded from this analysis, as were all patients enrolled in AAML1031's Arm D expansion cohort $(n=378)$ because response data were not collected for these patients. Patients who withdrew consent or went off-study for other reasons were censored at that date. 


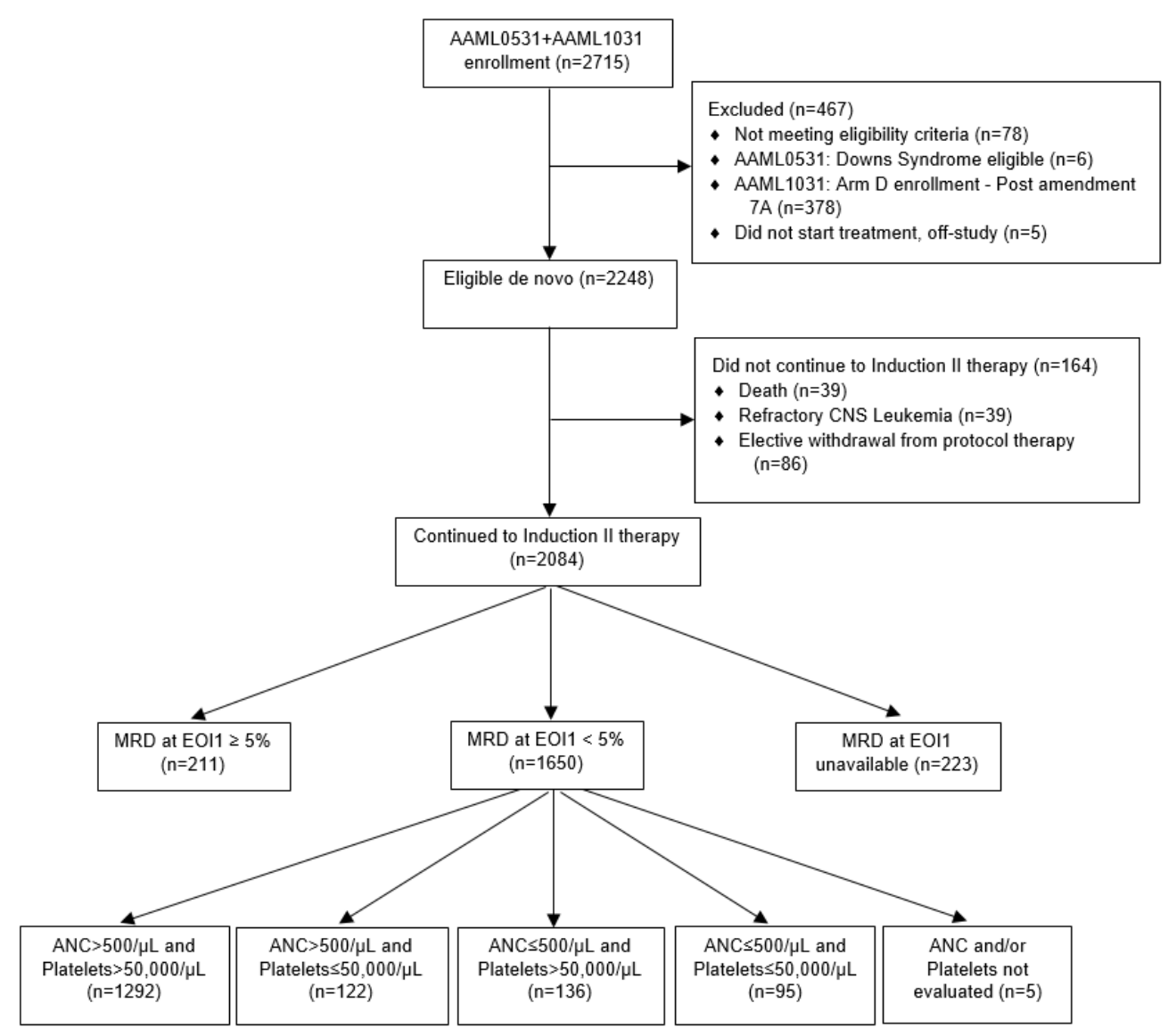

Figure 1. CONSORT diagram.

Among patients enrolled in both trials, 1861 (89.3\%) had RD assessed by centrally performed difference-from-normal $(\Delta \mathrm{N})$ flow cytometry at the end of induction I, which was previously shown to be superior to morphology in assessing response in children [11]. Those with $<5 \%$ RD by $\Delta \mathrm{N}(n=1645)$ achieved a complete response and were evaluated for time to and incidence of count recovery. Comprehensive CBC data were not collected for each patient. Instead, investigators were required to report whether patients achieved peripheral ANC of 500 cells $/ \mu \mathrm{L}$ and non-transfused platelet count of 50,000 cells $/ \mu \mathrm{L}$ prior to Induction II, and the date each parameter was achieved. Both COG trials recommended but did not require that Induction II begin when ANC $>1000$ cells $/ \mu \mathrm{L}$ and platelets $>75,000$ cells $/ \mu \mathrm{L}$ (Table 1). Survival analysis based on count recovery group was performed using disease-free survival (DFS) and overall survival (OS) from end of induction $\mathrm{I}$, and excluded the 60 patients in AAML1031 (Arm C) who received sorafenib for HAR FLT3-ITD disease ( $n=1585$; Figure 1$)$.

Table 1. Count recommendations for proceeding with the next cycle of chemotherapy.

\begin{tabular}{cccc}
\hline & $\begin{array}{c}\text { COG De Novo Cohort } \\
(\text { AAML0531 and AAML1031 } *)\end{array}$ & $\begin{array}{c}\text { Current COG AML Study } \\
\text { (AAML1831 *) }\end{array}$ & IWG/ELN \\
\hline ANC & $>1000$ cells $/ \mu \mathrm{L}$ & $>500$ cells $/ \mu \mathrm{L}$ & $>1000 \mathrm{cells} / \mu \mathrm{L}$ \\
\hline Platelets & $>75,000$ cells $/ \mu \mathrm{L}$ & $>50,000$ cells $/ \mu \mathrm{L}$ & $>100,000 \mathrm{cells} / \mu \mathrm{L}$ \\
\hline
\end{tabular}

Table Legend: * AAML0531 (NCT00372593), AAML1031 (NCT01371981), AAML1831 (NCT04293562); Abbreviations: AML, acute myeloid leukemia; ANC, absolute neutrophil count; COG, Children's Oncology Group; ELN, European LeukemiaNet; IWG, International Working Group. 


\subsection{Statistical Analysis}

Statistical analyses were performed with SAS version 9.4 (SAS Institute Inc., Cary, NC, USA). The Kaplan-Meier method was applied to estimate probabilities of survival with standard errors according to Greenwood and compared with the log-rank test [12]. Survival curves were compared using the log-rank test and based on count recovery (ANC $\geq 500$ cells $/ \mu \mathrm{L}$ only, platelets $\geq 50,000$ cells $/ \mu \mathrm{L}$ only, both ANC $\geq 500$ cells $/ \mu \mathrm{L}$ and platelets $\geq 50,000$ cells $/ \mu \mathrm{L}$, and neither ANC $\geq 500$ cells $/ \mu \mathrm{L}$ nor platelets $\geq 50,000$ cells $/ \mu \mathrm{L}$ ). OS was calculated from end of induction I to death of any cause, and DFS was defined as time from end of induction I to treatment failure, relapse, secondary malignancy, or death. Cumulative incidence functions of $\mathrm{ANC} /$ platelet recovery, relapse, or early death were constructed according to Kalbfleisch and Prentice [13]. The Cox proportional hazards model was used for multivariable analysis of outcomes [14]. For consistency in multivariable survival analysis, COG risk groups for this analysis were defined by current COG Phase 3 (AAML1831, NCT04293562) cytomolecular risk stratification and MRD [15] rather than original study-assigned risk group. Proportions were compared between groups using the chi-square test or Fisher's exact test when data were sparse. $p$ values $<0.05$ were considered significant. Living patients were censored at date of last follow-up. Data were frozen at 31 December 2019.

\section{Results}

\subsection{Proportion of Patients with Count Recovery}

Among all patients with fewer than $5 \%$ bone marrow AML blasts by centralized $\Delta \mathrm{N}$ flow cytometry $(n=1645)$, the proportion of patients who proceeded to Induction II prior to recovery of $\mathrm{ANC} \geq 500$ cells $/ \mu \mathrm{L}$ and platelet count $\geq 50,000$ cells $/ \mu \mathrm{L}$ was $21.5 \%(7.4 \%$ with ANC only $+8.3 \%$ with platelets only $+5.8 \%$ with neither ANC nor platelet recovery; Table 2).

Table 2. Count recovery following first induction on AAML0531 and AAML1031.

\begin{tabular}{|c|c|c|c|c|c|c|}
\hline & $\begin{array}{l}\text { Patients with }<5 \% \\
\text { Marrow Disease by } \\
\Delta \text { N Flow Cytometry }\end{array}$ & $\begin{array}{c}\text { ANC } \\
\text { Threshold } \\
\text { Only }(>500 / \mu L)\end{array}$ & $\begin{array}{c}\text { Platelet } \\
\text { Threshold } \\
\text { Only } \\
(>50,000 / \mu \mathrm{L})\end{array}$ & $\begin{array}{c}\text { Met Both } \\
(\text { ANC }>500 / \mu \mathrm{L} \text { and } \\
\text { Plt }>50,000 / \mu \mathrm{L})\end{array}$ & $\begin{array}{c}\text { Met Neither } \\
(\mathrm{ANC} \leq 500 / \mu \mathrm{L} \text { and } \\
\text { Plt } \leq 50,000 / \mu \mathrm{L})\end{array}$ & $\begin{array}{c}\text { ANC and/or } \\
\text { Platelets Not } \\
\text { Evaluated during } \\
\text { Reporting Period }\end{array}$ \\
\hline AAML0531 & 660 & $57(8.6 \%)$ & $55(8.3 \%)$ & $507(76.8 \%)$ & $41(6.2 \%)$ & $4(0.6 \%)$ \\
\hline AAML1031 & 985 & $65(6.6 \%)$ & $81(8.2 \%)$ & $785(79.7 \%)$ & $54(5.5 \%)$ & $1(0.1 \%)$ \\
\hline Combined & 1645 & $122(7.4 \%)$ & $136(8.3 \%)$ & $1292(78.5 \%)$ & $95(5.8 \%)$ & $5(0.3 \%)$ \\
\hline
\end{tabular}

Table abbreviations: ANC, absolute neutrophil count; $\Delta \mathrm{N}$, difference from normal; Plt, platelet.

In a cumulative incidence of count recovery analysis, $96.2 \%$ and $98.1 \%$ of patients recovered $\mathrm{ANC} \geq 500$ cells $/ \mu \mathrm{L}$ or platelet counts $\geq 50,000$ cells $/ \mu \mathrm{L}$ across the two Phase 3 COG trials at 42 and 49 days from the start of induction therapy, respectively. Only $86.3 \%$ and $92.4 \%$ reported recovery of both $\mathrm{ANC} \geq 500$ cells $/ \mu \mathrm{L}$ and platelets $\geq 50,000$ cells $/ \mu \mathrm{L}$ at 42 and 49 days from the start of induction therapy, respectively (Figure 2). Additional patient characteristics by count recovery group can be found in Supplemental Table S1. 


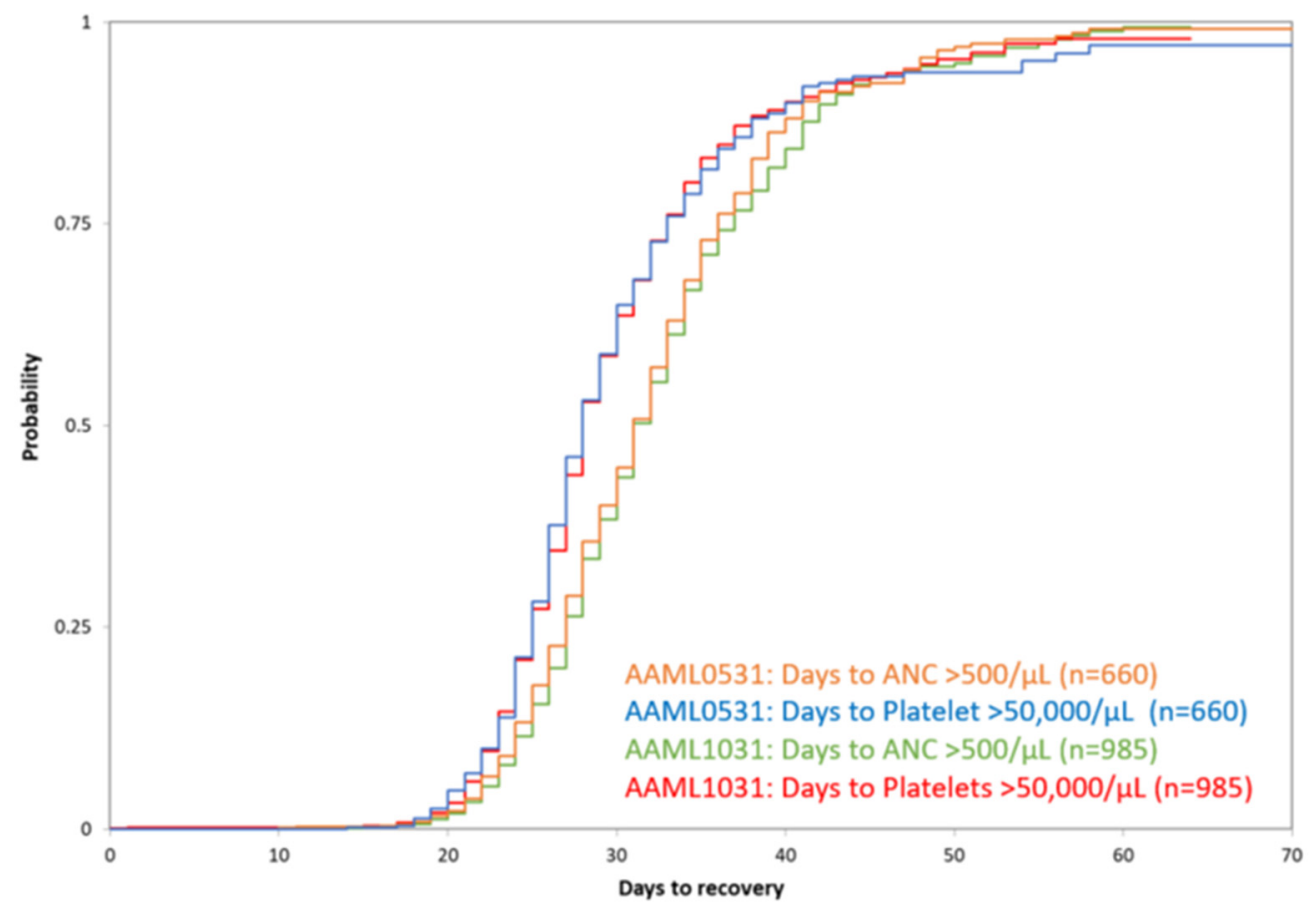

Figure 2. Cumulative incidence of count recovery. Count recovery in all patients with $\leq 5 \%$ bone marrow blasts by central $\Delta \mathrm{N}$ flow cytometry at the end of Induction I who went on to receive Induction II therapy on AAML0531 and AAML1031.

\subsection{Survival According to Count Recovery}

Survival analysis based on count recovery group was performed among patients with fewer than $5 \%$ bone marrow AML blasts by centralized $\Delta \mathrm{N}$ flow cytometry, and is reported in Figure 3. Median time to follow up for all patients alive at last contact was 4.7 years (range 0.2-7.6 years). Among responders, there was no significant association between count recovery parameters and five-year DFS $(p=0.843)$ or OS $(p=0.896)$ (Figure 3$)$ or RR (Supplemental Table S2). To address the trend of inferior outcomes for patients who recovered neither ANC nor platelets (Figure 3, green group), we compared that group to all other patients (Figure 3, red, blue and yellow groups). In that comparison, there was no significant difference in either five-year DFS $(46.1 \% \pm 11.0 \%$ vs. $51.8 \% \pm 2.6 \%$, respectively; $p=0.453)$ or OS $(62.2 \% \pm 11.5 \%$ vs. $68.8 \% \pm 2.5 \%$, respectively; $p=0.596)$. There was a trend toward decreased outcomes in the multivariable Cox analysis, as shown in Supplemental Tables S2 and S3. Variables which independently predicted outcomes included: sorafenib exposure for HAR FLT3-ITD patients in AAML1031, Gemtuzumab exposure in AAML0531, risk group stratification, WBC count at diagnosis, and HSCT in CR1 (Supplemental Table S2). An analysis comparing the individual treatment arms in each study also did not demonstrate that count recovery was predictive of EFS or OS (Supplemental Table S3). 

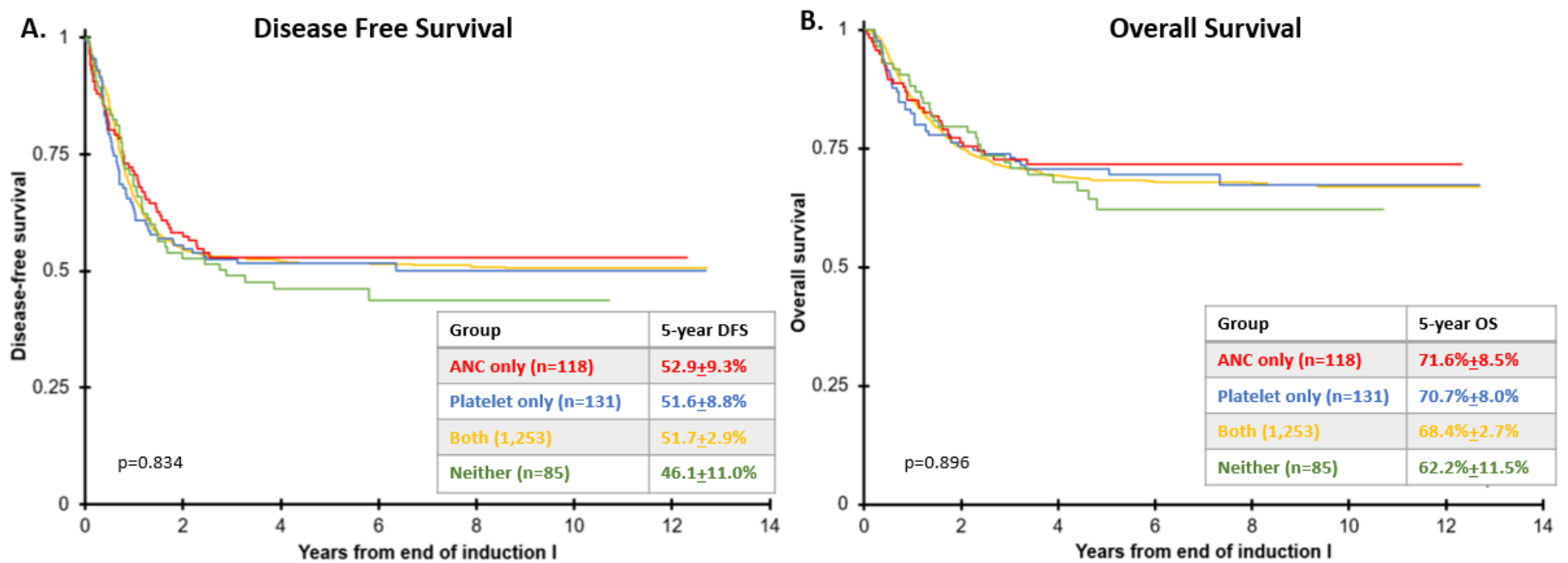

Figure 3. Survival by count recovery from end of induction I (EOI1). (A) Disease-free survival (DFS) and (B) overall survival (OS) from EOI1 are reported according to count recovery parameters in patients with $<5 \%$ bone marrow blasts by central $\Delta \mathrm{N}$ flow cytometry who received Induction I and II therapy in AAML0531 and AAML1031.

\section{Discussion}

4.1. Waiting for Count Recovery per IWG/ELN Criteria for CR Does Not Reflect Standard Practice in Pediatric AML

The standard AML treatment approach over the past 40 years for both children and adults has been anthracyclines combined with cytarabine, though the therapeutic landscape is now evolving to include more targeted therapies. We now have a better understanding of AML biology, response, risk classification, and the impact of each on survival. Accordingly, as we evaluate therapies for children, we must define relevant response criteria in childhood AML to support the development of promising new therapies to advance cures. Delays in count recovery in adults with AML are thought to reflect the persistence of leukemia, often with a myelodysplasia (MDS) phenotype. Childhood AML often has more aggressive biology compared to that in adults and the MDS phenotype is quite rare [3,4]. Awaiting marrow recovery to IWG/ELN defined count thresholds has not been the recommended practice in pediatric AML Phase 3 trials. Pediatric patients often start subsequent chemotherapy cycles prior to count recovery to IWG/ELN parameters (Table 1) because dose timing and intensification has demonstrated improved outcomes in both North American and European trials for de novo pediatric AML [16,17]. In the most recent completed COG Phase 3 trials, $21.5 \%$ of patients proceeded to a second cycle of induction therapy prior to recovering ANC $>500$ cells $/ \mu \mathrm{L}$ and/or platelets $>50,000$ cells $/ \mu \mathrm{L}$ (Table 1 ), which are well below the IWG/ELN criteria of ANC > 1000 cells / uL and platelets $>100,000$ cells $/ \mathrm{uL}$. The current COG de novo AML Phase 3 study, AAML1831 (NCT0429356), recommends that subsequent cycles of therapy should begin when ANC $>500$ cell $/ \mathrm{uL}$ and platelets $>50,000$ cells $/ \mathrm{uL}$ (Table 1). The AAML1831 study committee implemented these recommendations based on observations from AAML0531/1031 that investigators were not waiting for count recovery to suggested parameters (personal communication). Contrary to the findings of Walter et al., the data from AAML0531/1031 confirm that a significant proportion of pediatric patients do not reach the IWG/ELN thresholds for recovery before the start of subsequent therapeutic cycles and highlight the prioritization of therapy intensification by pediatric oncologists over complete hematopoietic regeneration.

\subsection{Count Recovery Does Not Significantly Impact Survival in These Large Pediatric Datasets}

The current IWG/ELN criteria for response imply that the absence of full hematopoietic recovery (ANC > 1000 cells $/ \mathrm{uL}$ and plt $>100$ cells $/ \mathrm{uL}$ ) is prognostic in adults with AML. Although retrospective studies have suggested inferior outcomes for adult patients 
with CRi/CRp compared to those with CR [8,18], this has never been validated in pediatric AML patients. While our pediatric cohort is not adequately powered to specifically answer this survival question, it represents the largest US dataset available to review incidence and survival associated with count recovery, and the sample size is comparable to the Walter cohort [8]. Our retrospective evaluation of the available COG de novo AML data was unable to detect a significant difference in DFS and OS based on ANC and platelet recovery in children (Figure 3). Likewise, recent BFM data also confirm that count recovery does not predict survival in the setting of first relapse of AML $[19,20]$. Although in Figure 3 the DFS and OS appear lower in the COG cohort without ANC or platelet recovery by the end of induction I, this trend was not statistically significant. We do note that the number of patients with EOI1 MRD positivity, a known prognostic factor, was higher in the cohort without ANC and platelet recovery when compared to other cohorts $(p=0.063)$ (Supplemental Table S1). Survival in all COG cohort groups was comparable until two years of follow-up, after which six patients in AAML0531 experienced late relapses. MRD rates were similar between these late relapse patients and the rest of the cohorts.

One of the limitations of this study is the lack of detailed end-of-induction CBC data for each patient enrolled in these clinical trials. Therefore, we are unable to directly refute the IWG/ELN CR criteria (ANC $\geq 1000$ cells $/ \mu \mathrm{L}$ and platelets $\geq 100,000$ cells $/ \mu \mathrm{L}$ ). As described above, it is not common practice for physicians treating childhood AML to wait for count recovery to these thresholds, and therefore, cut-offs of ANC $\geq 500$ of cells $/ \mu \mathrm{L}$ and platelets $\geq 50,000$ cells $/ \mu \mathrm{L}$ were used for data analysis. Data from our colleagues in the International Berlin-Frankfurt-Munster (i-BFM) group confirm this practice, demonstrating that only one-third of patients achieve recovery to IWG/ELN criteria after AML induction (personal communication, Dirk Rheinhardt). It is possible that strict adherence to waiting for count recovery to the IWG/ELN criteria might show more significant survival differences among these groups.

\subsection{Cheson Criteria Should Be Reconsidered as the Standard Response Evaluation in Children with} AML, and Perhaps Also in Adults

The current IWG and ELN criteria were based upon retrospective data in adults supporting prolonged survival for patients who achieve CR [8]. Specifically, Walter et al. demonstrated that among 1321 patients treated between 1984 and 2004, CR was independently associated with a longer relapse-free survival relative to CRp [8]. In comparison to the COG experience, the Walter et al. data demonstrate clear differences in tolerance for waiting for full count recovery that may be influenced by the underlying biology of adult AML compared to childhood AML. Despite this, CR by IWG/ELN criteria are the standard applied by regulatory authorities to new drug approvals in children. The Food and Drug Administration goes so far as to define a treatment failure as a failure to achieve CR by IWG criteria [21]. As we consider how best to assess response in children with AML, we must consider that the standards of care for children and adults captured in this dataset are clearly and substantially different. Therefore, using the IWG/ELN criteria risks an underestimate of response in children, even if CRp is included in the overall response assessment.

Although CR per IWG and ELN criteria has historically been used as a surrogate for survival in adults, recent studies question the reliable association between CR and survival, suggesting it may be time to reconsider these definitions for response evaluation in both adult and pediatric AML [22]. Multiple recent adult studies have demonstrated significant improvements in CR rates without improvement in survival $[23,24]$, inferior CR rates with comparable survival [25,26], and absence of CR with improved survival [27]. These data suggest that response, as currently defined by the IWG/ELN, may over- or underestimate survival in adults with AML treated with contemporary therapies. 


\section{Conclusions}

In the largest available US pediatric cohort, we are unable to confirm an association between peripheral blood count recovery and survival, despite a comparable sample size to the Walter et al. cohort. Continuing to use adult IWG/ELN response assessment definitions places severe limitations on childhood AML drug development by classifying lack of CR using these guidelines as treatment failure. Additionally, these definitions are not aligned with the standard of care for intensification of pediatric AML therapy and are not followed by pediatric oncologists.

Given the data presented here, response criteria must be reconsidered for pediatric patients with AML. International cooperative groups are currently working to compile new, standard definitions for both count recovery thresholds and remission status in order to more accurately define treatment responses in future pediatric AML trials. In the meantime, we propose that $\mathrm{CR}, \mathrm{CRp}$ and $\mathrm{CRi}$ are all valid primary study endpoints.

Supplementary Materials: The following supporting information can be downloaded at: https: / / www.mdpi.com/article/10.3390/cancers14030616/s1, Table S1. Patient characteristics by count recovery. Table S2. Multivariable analysis for overall survival (OS), disease free survival (DFS), and relapse risk (RR) from end of induction I. Table S3. Multivariable analysis for overall survival (OS), disease free survival (DFS), and relapse risk (RR) from end of induction I by study treatment arm.

Author Contributions: Conceptualization, T.M.C. and E.A.K.; methodology, T.M.C., E.A.K. and T.A.A.; formal analysis, R.B.G. and T.A.A.; writing-original draft preparation, L.P., T.M.C. and E.A.K.; writing-review and editing, L.B., M.L., A.G., R.A., T.A.A. and R.B.G. All authors have read and agreed to the published version of the manuscript.

Funding: Supported by St. Baldrick's Foundation, the Leukemia and Lymphoma Society Children's Initiative (TMC, EAK), the Leukemia Research Foundation of Delaware (EAK), the National Cancer Institution of the National Institutes of Health National Clinical Trials Network (NCTN) Operations Center grant U10CA180886, NCTN Statistics \& Data Center Grant U10CA180899 (TAA), the Children's Oncology Group Chair's Grant U10CA098543, and the Statistics and Data Center Grant U10CA098413.

Institutional Review Board Statement: The retrospective analysis and all included studies were performed in accordance with the Declaration of Helsinki. AAML0531 and AAML1031 were conducted by the Children's Oncology Group. Each study was approved by the Pediatric Central Institutional Review Board at the National Cancer Institute in compliance with the United States Code of Federal Regulations and by appropriate ethics authorities at each participating COG member site.

Informed Consent Statement: Informed consent was obtained from all subjects involved in the study.

Data Availability Statement: The Children's Oncology Group Data Sharing policy describes the release and use of COG individual subject data for use in research projects in accordance with National Clinical Trials Network (NCTN) Program and NCI Community Oncology Research Program (NCORP) Guidelines. Only data expressly released from the oversight of the relevant COG Data and Safety Monitoring Committee (DSMC) are available to be shared. Data sharing will ordinarily be considered only after the primary study manuscript is accepted for publication. For phase 3 studies, individual-level de-identified datasets that would be sufficient to reproduce results provided in a publication containing the primary study analysis can be requested from the NCTN/NCORP Data Archive at https://nctn-data-archive.nci.nih.gov/, accessed on 22 November 2021. Data are available to researchers who wish to analyze the data in secondary studies to enhance the public health benefit of the original work and agree to the terms and conditions of use. For nonphase 3 studies, data are available following the primary publication. An individual-level deidentified dataset containing the variables analyzed in the primary results paper can be expected to be available upon request. Requests for access to COG protocol research data should be sent to: datarequest@childrensoncologygroup.org. Data are available to researchers whose proposed analysis is found by COG to be feasible and of scientific merit and who agree to the terms and conditions of use. For all requests, no other study documents, including the protocol, will be made available and no end date exists for requests. In addition to above, release of data collected in a clinical trial conducted under a binding collaborative agreement between COG or the NCI Cancer Therapy Evaluation 
Program (CTEP) and a pharmaceutical/biotechnology company must comply with the data sharing terms of the binding collaborative/contractual agreement and must receive the proper approvals.

Acknowledgments: To Dirk Reinhardt for his review of the data and discussion of the key issues.

Conflicts of Interest: Michael Loken and Lisa Brodersen are both employed and have equity ownership in Hematologics, Inc. The other authors declare no conflict of interest.

\section{References}

1. Puumala, S.E.; Ross, J.A.; Aplenc, R.; Spector, L. Epidemiology of childhood acute myeloid leukemia. Pediatr. Blood Cancer 2013, 60, 728-733. [CrossRef] [PubMed]

2. Arber, D.A.; Orazi, A.; Hasserjian, R.; Thiele, J.; Borowitz, M.J.; Le Beau, M.M.; Bloomfied, C.D.; Cazzola, M.; Vardiman, J.W. The 2016 revision to the World Health Organization classification of myeloid neoplasms and acute leukemia. Blood 2016, 127, 2391-2405. [CrossRef] [PubMed]

3. Bolouri, H.; Farrar, J.E.; Triche, T., Jr.; Ries, R.E.; Lim, E.L.; Alonzo, T.A.; Ma, Y.; Moore, R.; Mungal, A.J.; Marra, M.A.; et al. The molecular landscape of pediatric acute myeloid leukemia reveals recurrent structural alterations and age-specific mutational interactions. Nat. Med. 2018, 24, 103-112. [CrossRef] [PubMed]

4. Tarlock, K.; Zhong, S.; He, Y.; Ries, R.; Severson, E.; Bailey, M.; Morley, S.; Balasubramanian, S.; Erlich, R.; Lipson, D.; et al. Distinct age-associated molecular profiles in acute myeloid leukemia defined by comprehensive clinical genomic profiling. Oncotarget 2018, 9, 26417-26430. [CrossRef]

5. Cheson, B.D.; Cassileth, P.A.; Head, D.R.; Schiffer, C.A.; Bennett, J.M.; Bloomfield, C.D.; Brunning, R.; Gale, R.P.; Grever, M.R.; Keating, M.J. Report of the National Cancer Institute-sponsored workshop on definitions of diagnosis and response in acute myeloid leukemia. J. Clin. Oncol. 1990, 8, 813-819. [CrossRef]

6. Cheson, B.D.; Bennett, J.M.; Kopecky, K.J.; Büchner, T.; Willman, C.L.; Estey, E.H.; Schiffer, C.A.; Doehner, H.; Tallman, M.S.; Lister, T.A.; et al. Revised Recommendations of the International Working Group for Diagnosis, Standardization of Response Criteria, Treatment Outcomes, and Reporting Standards for Therapeutic Trials in Acute Myeloid Leukemia. J. Clin. Oncol. 2003, 21, 4642-4649. [CrossRef]

7. Döhner, H.; Estey, E.H.; Amadori, S.; Appelbaum, F.R.; Büchner, T.; Burnett, A.K.; Dombret, H.; Fenaux, P.; Grimwade, D.; Larson, R.A.; et al. Diagnosis and management of acute myeloid leukemia in adults: Recommendations from an international expert panel, on behalf of the European LeukemiaNet. Blood 2010, 115, 453-474. [CrossRef]

8. Walter, R.B.; Kantarjian, H.M.; Huang, X.; Pierce, S.A.; Sun, Z.; Gundacker, H.M.; Ravandi, F.; Faderl, S.H.; Tallman, M.S.; Appelbaum, F.R.; et al. Effect of Complete Remission and Responses Less Than Complete Remission on Survival in Acute Myeloid Leukemia: A Combined Eastern Cooperative Oncology Group, Southwest Oncology Group, and M. D. Anderson Cancer Center Study. J. Clin. Oncol. 2010, 28, 1766-1771. [CrossRef]

9. Gamis, A.S.; Alonzo, T.A.; Meshinchi, S.; Sung, L.; Gerbing, R.B.; Raimondi, S.C.; Hirsch, B.A.; Kahwash, S.B.; Winter, L.; Glick, K. Gemtuzumab ozogamicin in children and adolescents with de novo acute myeloid leukemia improves event-free survival by reducing relapse risk: Results from the randomized phase III Children's Oncology Group trial AAML. J. Clin. Oncol. 2014, 32, 3021-3032. [CrossRef]

10. Aplenc, R.; Meshinchi, S.; Sung, L.; Alonzo, T.; Choi, J.; Fisher, B.; Gerbing, R.; Hirsch, B.; Horton, T.; Kahwash, S.; et al. Bortezomib with standard chemotherapy for children with acute myeloid leukemia does not improve treatment outcomes: A report from the Children's Oncology Group. Haematologica 2020, 105, 1879-1886. [CrossRef]

11. Brodersen, L.E.; Gerbing, R.B.; Pardo, M.L.; Alonzo, T.A.; Paine, D.; Fritschle, W.; Hsu, F.-C.; Pollard, J.A.; Aplenc, R.; Kahwash, S.B.; et al. Morphologic remission status is limited compared to DeltaN flow cytometry: A Children's Oncology Group AAML0531 report. Blood Adv. 2020, 4, 5050-5061. [CrossRef] [PubMed]

12. Kaplan, E.L.; Meier, P. Nonparametric Estimation from Incomplete Observations. J. Am. Stat. Assoc. 1958, 53, 457. [CrossRef]

13. Kalbfleisch, J.; Prentice, R. The Statistical Analysis of Failure Time Data; John Wiley: New York, NY, USA, 1980.

14. Cox, D.R. Regression Models and Life-Tables. Breakthr. Stat. 1992, 527-541. [CrossRef]

15. Cooper, T.M.; Ries, R.E.; Alonzo, T.A.; Gerbing, R.B.; Loken, M.R.; Brodersen, L.E.; Raimondi, S.C.; Hirsch, B.A.; Aplenc, R.; Gamis, A.S.; et al. Revised Risk Stratification Criteria for Children with Newly Diagnosed Acute Myeloid Leukemia: A Report from the Children's Oncology Group. Blood 2017, 130, 407.

16. Lange, B.J.; Smith, F.O.; Feusner, J.; Barnard, D.R.; Dinndorf, P.; Feig, S.; Heerema, N.A.; Arndt, C.; Arceci, R.J.; Seibel, N.; et al. Outcomes in CCG-2961, a children's oncology group phase 3 trial for untreated pediatric acute myeloid leukemia: A report from the children's oncology group. Blood 2008, 111, 1044-1053. [CrossRef] [PubMed]

17. Abrahamsson, J.; Forestier, E.; Heldrup, J.; Jahnukainen, K.; Jónsson, G.; Lausen, B.; Palle, J.; Zeller, B.; Hasle, H. Response-Guided Induction Therapy in Pediatric Acute Myeloid Leukemia with Excellent Remission Rate. J. Clin. Oncol. 2011, $29,310-315$. [CrossRef] [PubMed]

18. Chen, X.; Xie, H.; Wood, B.L.; Walter, R.; Pagel, J.M.; Becker, P.S.; Sandhu, V.K.; Abkowitz, J.L.; Appelbaum, F.R.; Estey, E.H. Relation of Clinical Response and Minimal Residual Disease and Their Prognostic Impact on Outcome in Acute Myeloid Leukemia. J. Clin. Oncol. 2015, 33, 1258-1264. [CrossRef] 
19. Kaspers, G.J.L.; Zimmermann, M.; Reinhardt, D.; Gibson, B.E.S.; Tamminga, R.Y.J.; Aleinikova, O.; Armendariz, H.; Dworzak, M.; Ha, S.-Y.; Hasle, H.; et al. Improved Outcome in Pediatric Relapsed Acute Myeloid Leukemia: Results of a Randomized Trial on Liposomal Daunorubicin by the International BFM Study Group. J. Clin. Oncol. 2013, 31, 599-607. [CrossRef]

20. Rasche, M.; Zimmermann, M.; Steidel, E.; Alonzo, T.; Aplenc, R.; Bourquin, J.-P.; Boztug, H.; Cooper, T.; Gamis, A.; Gerbing, R.; et al. Survival Following Relapse in Children with Acute Myeloid Leukemia: A Report from AML-BFM and COG. Cancers 2021 13, 2336. [CrossRef]

21. U.S. Department of Health and Human Services Food and Drug Administrations. Acute Myeloid Leukemia: Developing Drugs and Biological Products for Treatment; Guidance for Industry. August 2020. Available online: https://www.fda.gov/media/1408 21/download (accessed on 22 September 2021).

22. Bloomfield, C.D.; Estey, E.; Pleyer, L.; Schuh, A.C.; Stein, E.M.; Tallman, M.S.; Wei, A. Time to repeal and replace response criteria for acute myeloid leukemia? Blood Rev. 2018, 32, 416-425. [CrossRef]

23. Burnett, A.K.; Hills, R.K.; Hunter, A.E.; Milligan, D.; Kell, W.J.; Wheatley, K.; Yin, J.; McMullin, M.F.; Dignum, H.; Bowen, D.; et al. The addition of gemtuzumab ozogamicin to low-dose Ara-C improves remission rate but does not significantly prolong survival in older patients with acute myeloid leukaemia: Results from the LRF AML14 and NCRI AML16 pick-a-winner comparison. Leukemia 2013, 27, 75-81. [CrossRef] [PubMed]

24. Burnett, A.K.; Russell, N.H.; Hunter, A.E.; Milligan, D.; Knapper, S.; Wheatley, K.; Yin, J.; McMullin, M.F.; Ali, S.; Bowen, D.; et al. Clofarabine doubles the response rate in older patients with acute myeloid leukemia but does not improve survival. Blood 2013, 122, 1384-1394. [CrossRef] [PubMed]

25. $\quad$ van der Helm, L.H.; Scheepers, E.R.; Veeger, N.J.; Daenen, S.M.; Mulder, A.B.; van den Berg, E.; Vellenga, E.; Huls, G. Azacitidine might be beneficial in a subgroup of older AML patients compared to intensive chemotherapy: A single centre retrospective study of 227 consecutive patients. J. Hematol. Oncol. 2013, 6, 29. [CrossRef] [PubMed]

26. Gupta, N.; Miller, A.; Gandhi, S.; Ford, L.A.; Vigil, C.E.; Griffiths, E.A.; Thompson, J.E.; Wetzler, M.; Wang, E.S. Comparison of epigenetic versus standard induction chemotherapy for newly diagnosed acute myeloid leukemia patients $>/=60$ years old. Am. J. Hematol. 2015, 90, 639-646. [CrossRef] [PubMed]

27. Stein, E.M.; Dinardo, C.D.; Pollyea, D.A.; Fathi, A.T.; Roboz, G.J.; Altman, J.K.; Stone, R.M.; DeAngelo, D.J.; Levine, R.L.; Flinn, I.W.; et al. Enasidenib in mutant IDH2 relapsed or refractory acute myeloid leukemia. Blood 2017, 130, 722-731. [CrossRef] 